7. Child Lang. 40 (2013), 779-798. (c) Cambridge University Press 2012.

The online version of this article is published within an Open Access environment subject to the conditions of the Creative Commons Attribution-NonCommercial-

ShareAlike licence $<$ http://creativecommons.org/licenses/by-nc-sa/2.5/ $>$. The written permission of Cambridge University Press must be obtained for commercial re-use. doi:I0.IOI 7/So3050009I 2000244

\title{
Characteristics of early vocabulary and grammar development in Slovenian-speaking infants and toddlers: a CDI-adaptation study*
}

\author{
LJUBICA MARJANOVIČ-UMEK, \\ URŠKA FEKONJA-PEKLAJ AND ANJA PODLESEK \\ University of Ljubljana, Faculty of Arts - Department of Psychology \\ (Received 22 Fune 201 - Revised I February 2012-Accepted I7 May 2012- \\ First published online 6 August 2012)
}

\begin{abstract}
A large body of research shows that vocabulary does not develop independently of grammar, representing a better predictor of the grammatical complexity of toddlers' utterances than age. This study examines for the first time the characteristics of vocabulary and grammar development in Slovenian-speaking infants and toddlers using the Slovenian adaptation of the MacArthur-Bates Communicative Development Inventories (CDI). The sample included 5 I 2 Slovenian-speaking infants and toddlers aged $0 ; 8$ to $2 ; 6$. The findings suggest that between age $0 ; 8$ and $2 ; 6$ the development of vocabulary is best described using a quadratic function. The results also show that nouns predominate in the vocabularies of infants and toddlers of various ages; as they age and with the increasing size of their vocabularies, the share of interjections decreases and the share of verbs and adjectives increases. The size of vocabulary was also found to be related to the grammatical structure of toddlers' utterances.
\end{abstract}

\section{INTRODUCTION}

There is very little research on the early language development of Slovenian-speaking infants and toddlers, which to date has limited our understanding of acquiring Slovenian and the relationship between various aspects of early language development. In addition, the lack of empirical data has made it impossible to compare the process of acquiring Slovenian

[*] Address for correspondence: Urška Fekonja-Peklaj, University of Ljubljana, Faculty of Arts - Department of Psychology, Aškerčeva 2 Ljubljana ıooo, Slovenia. e-mail: urska. fekonja@ff.uni-lj.si 
vocabulary and grammar with the process of acquiring other languages. This is the first study to provide a detailed examination of the early acquisition of vocabulary and grammar based on a sample of Slovenianspeaking infants and toddlers aged $0 ; 8$ to $2 ; 6$, using the Slovenian adaptation of the MacArthur-Bates Communicative Development Inventories (CDI; Fenson et al., I 994). This adaptation makes it possible to compare the results obtained with the results of other studies, in which researchers used the CDI as a measure of toddlers' language in other linguistic environments. To this end, we present the findings of certain studies in which researchers studied toddlers' vocabulary in other linguistic environments as a measure for predicting their acquisition of grammar.

\section{The characteristics of early vocabulary development and its relationship to the acquisition of grammar}

The results of the studies in which researchers have used adaptations of the CDI in various languages - for example, English (Fenson et al., I 994), Italian (Devescovi, Caselli, Marchione, Pasqualetti, Reilly \& Bates, 2005), Danish (Bleses et al., 2008), and Finnish (Stolt, Haataja, Lapinleimu \& Lehtonen, 2009) - to assess early vocabulary and grammar indicate specific similarities in the development of vocabulary and grammar among infants and toddlers speaking different languages. Researchers have established that vocabulary develops rapidly during toddlerhood (Brooks \& Meltzoff, 2008; Fenson et al., I994), while toddlers are typically able to understand words before they can use them (Bates \& Goodman, 200 I; Fenson et al., I 994). Most toddlers speak their first word between the ages of $\mathbf{I}$; 0 and $\mathbf{I} ; 8$, although there are large individual differences among them (Bleses et al., 2008; Devescovi et al., 2005; Fenson et al., I 994; Fernald, Pinto, Swingley, Weinberg \& McRoberts, 200I). These individual differences can be illustrated by the findings of Bates et al. (r994), showing that infants aged I ; O spoke $\circ$ to 52 words, those aged I; 4 spoke $\circ$ to 347 words, and those aged 2;6 spoke 208 to 675 words. After I; 6, toddlers' vocabulary size increases very quickly (Bates \& Goodman, $200 \mathrm{I}$; Fernald et al., 200 I). Bates and Goodman (200I) found that there are two important leaps in toddlers' vocabulary development: the first one occurs between ages I ; 4 and I ; 8, and the second between $2 ; 0$ and $2 ; 6$, during which the range of vocabulary may increase by a few words each day, but not all toddlers experience these leaps in vocabulary development at the same age (Hoff, 200 I; Reznick \& Goldfield, I 994).

The first words in toddlers' vocabulary are most often connected with naming things in their immediate environment and they primarily refer to family members, food, animals, parts of the body, and routine activities, or they involve simple requests that the child uses to ask adults for help 
(Caselli, Casadio \& Bates, 200 I; Karmiloff \& Karmiloff-Smith, 200 I ; Siegler, I998). With the mastery of the grammar of the language and with the development of multiword utterances, toddlers' language also includes an increasing number of adjectives that they use to name the qualities of objects and the relationships between them, as well as a growing number of function words (Caselli et al., 200 г Owens, I 996). Several researchers (e.g. Bates \& Goodman, I997; Bates, Dale \& Thal, I995; Conboy \& Thal, 2006) have established that toddlers tend to speak open-class or content words such as nouns, verbs and adjectives earlier than closed-class or grammatical words such as prepositions, determiners and pronouns. At first, the share of common nouns increases, but then begins to decrease with increasing vocabulary. The case is similar with words denoting social relationships, which are frequent among toddlers' first words, but later on, when toddlers also begin to use other word types, their share begins to decrease. On the one hand, toddlers' ability to acquire closed-class words reflects the development of their cognitive abilities and, on the other hand, it depends on a sufficient number of open-class words in the toddlers' vocabulary. Toddlers first use open-class words to name things in their environment; they only later place them in various relationships using closed-class words, which Bates and Goodman (1997) refer to as logical bootstrapping. So, for example, toddlers' acquisition of adjectives is connected with their previous acquisition of nouns, and the acquisition of grammatical words is connected with their previous acquisition of nouns and adjectives (Conboy \& Thal, 2006). Morgan, Shi and Allopena (r 996) claim that closed-class words probably occur later in toddlers' vocabulary because they are less emphasized in speech and are phonologically shorter; this is why toddlers acquire them later than open-class words.

The findings of studies that used parents' assessments on the CDI as the measure of infants'/toddlers' language (e.g. Bates \& Goodman, I997; Conboy \& Thal, 2006; Stolt et al., 2009) show that the development of toddlers' vocabulary is connected with the development of grammar. Marchman and Bates (I994), amongst others, argue that toddlers can transition from forming single-word utterances to two-word utterances when their vocabularies contain from 50 to roo words, suggesting the existence of a relationship between lexical and grammar acquisition. Bates and Goodman (200I) report that the content and character of toddlers' first word combinations in utterances is significantly linked to the content and character of their single-word utterances. The size of the vocabularies of the infants aged $\mathrm{I} ; 8$ that they studied was significant in predicting the complexity of grammar in the toddlers' language at 2;4. Bates (I999) illustrates this powerful relationship between toddlers' vocabulary and grammar by the description of the growth of grammatical complexity of toddlers' sentences as a function of vocabulary size. However, several 
researchers (e.g. Bates, I999; Devescovi et al., 2005) have established that the size of toddlers' vocabulary better predicts the development of grammar than toddlers' age and gender.

Conboy and Thal (2006) emphasize that the correlation between toddlers' acquisition of vocabulary and grammar is manifested in the relatively late emergence of grammatical words in their vocabulary; the frequency of these words increases with the size of vocabulary between the ages of I; 6 and 2;6 and enables toddlers to form grammatically more complex utterances. The correlation between the development of vocabulary and grammar is generally typical of toddlers that speak various languages, but sociolinguistic and typological differences can result in different shares of individual word types in their vocabulary (for reviews, see Conboy \& Thal, 2006). Thus, for example, the larger share of verbs in the early vocabulary of Korean-speaking toddlers reflects the predominance of activity-oriented utterances over naming-oriented utterances in Korean, the frequent use of utterances that include only a verb, and sentence-final placement of verbs. The established differences in the vocabulary of toddlers speaking different languages (e.g. Korean and Mandarin Chinese) can also result from the methodological approach to language assessment because assessment of Korean toddlers' spontaneous speech shows a high percentage of verbs in their vocabulary, whereas the parental assessments show a higher percentage of nouns (Conboy \& Thal, 2006; Tardif, Gelman \& Xu, I999). Bornstein et al. (2004) analyzed the vocabularies of infants aged I;8 that spoke various languages (Spanish, Dutch, French, Hebrew, Italian, Korean and English) and lived in various linguistic environments. They determined that nouns predominated over all other groups of words in toddlers' vocabulary, but only in toddlers that used more than 50 words. In the vocabulary of toddlers that used up to 50 words, the share of nouns and verbs was comparable. However, Devescovi et al. (2005) have established that the vocabulary of Italian-speaking toddlers aged I;6 to $2 ; 6$ evaluated using the CDI is characterized by a higher percentage of social words compared to the vocabulary of English-speaking toddlers. In addition, they found that the correlation between the mean length of utterance (MLU) and vocabulary size of Italian-speaking toddlers is linear, whereas in English-speaking toddlers the correlation between these two measures is non-linear. Icelandic researchers have compared English- and Icelandicspeaking toddlers and established certain differences in the relationship between the vocabulary and the grammatical complexity of toddler's utterances evaluated using the CDI (Thordardottir, Weismer \& Evans, 2002); they connect the differences ascertained with the more complex inflectional system in Icelandic.

The main objective of our study was to establish the characteristics of early acquisition of vocabulary and grammar in Slovenian-speaking infants 
and toddlers aged $0 ; 8$ to $2 ; 6$, as indexed by the CDI parental reports. Our research goal was a detailed analysis of early vocabulary regarding its growth and word-type structure. Furthermore, we analyzed the relationship between infants'/toddlers' vocabulary and the use of communicative gestures and grammar to establish the predictive value of infants' and toddlers' vocabularies for their communicative abilities, such as the use of communicative gestures and forming multiword and grammatically complex utterances. We tried to establish whether Slovenian grammatical features could affect toddlers' acquisition of grammar and result in potentially different relationships between vocabulary size and the grammatical structure of toddlers' utterances more than is normally the case in English.

\section{METHOD}

\section{Participants}

The sample included 5 I 2 Slovenian infants and toddlers aged from $0 ; 8$ to 2;6. There were I 52 infants and toddlers aged $0 ; 8$ to I;4 (72 boys and 80 girls), and 360 toddlers aged I 4 to $2 ; 6$ ( 186 boys and I 74 girls). All the infants and toddlers were full-term at birth, and had no serious illness or developmental delays. Infants and toddlers were recruited for the sample in three ways: through preschools, health clinics for preschool children, and parenting websites. The sample included only infants and toddlers for whom parents submitted written permission to participate in the study. The educational structure of infants' and toddlers' mothers that completed the CDI : Words and Gestures questionnaire was as follows: $2 \cdot 7 \%$ of mothers had completed only primary school; $26 \%$ had a secondary-school degree (vocational school or college-prep high school); and $7 \mathrm{I} \cdot 3 \%$ had a tertiary education (associate's, bachelor's, master's, or doctoral degree). The sample of infants and toddlers is slightly biased given the disproportionately low share of mothers with an extremely low (primary) education and the high share of mothers with a tertiary education.

\section{Materials}

To assess the communicative competence of infants and toddlers we used a Slovene adaptation of the MacArthur-Bates Communicative Development Inventories (CDI; Fenson et al., I 994). The communicative competence of infants and toddlers from aged $0 ; 8$ to $\mathrm{I} ; 4$ was assessed using the CDI: Words and Gestures (Marjanovič-Umek, Fekonja-Peklaj, Sočan \& Komidar, 20II), while the communicative competence of toddlers from I ; 4 to 2;6 was assessed using the CDI: Words and Sentences (MarjanovičUmek, Fekonja-Peklaj, Sočan \& Komidar, 20I I). The CDI: Words and 
Gestures consists of two parts. Part I includes four sections: First Signs of Understanding, Phrases, Beginning to Talk, and Vocabulary (includes a checklist of 394 words divided into I9 groups). Part II, Actions and Gestures, includes six sections: First Communicative Gestures, Games and Routines, Actions with Objects, Imitating Adult Actions, Pretending to Be a Parent, and Object Substitutions. The CDI : Words and Sentences consists of two parts. Part I: Words Used by Toddlers consists of two sections: Vocabulary (contains a checklist of 680 words divided into 22 groups) and Past and Future Activities and Absent Things or Persons. The second part of the checklist, entitled Part II: Sentences and Grammar, includes the following sections: Word Form and Meaning, Overgeneralization of Syntax Rules, Mean Length of Utterance, and Sentence Complexity.

The Slovenian adaptations preserved all of the sections included in the original inventories as well as the same number of words, included in the Vocabulary section. However, individual items that are not transferable into Slovenian at the translation level were changed and new items were added that refer to specific features of Slovenian. Slovenian is a Slavic language and is one of the few Indo-European languages that has preserved the dual number and continues to use it extensively (e.g. ena hiša 'one house', dve hiši 'two houses', tri hiše 'three houses'). In contrast to English, Slovenian is characterized by a relatively complex system of nominal declension (Slovenian uses four feminine, four masculine and four neuter declensions) and verb conjugation (e.g. the verb hoditi 'walk' is conjugated in the following manner: jaz hodi-m 'I walk', $t i$ hodi-š 'you walk', on hodi 'he walks', mi hodi-mo 'we walk', vi hodi-te 'you walk', oni hodi-jo 'they walk'). The major changes made in the adaptation process, which reflect the characteristics and cultural context of Slovenian, are: (a) several words were replaced in the Vocabulary section of the CDI: Words and Gestures and the CDI: Words and Sentences because they are not typical of the Slovenian cultural environment and toddlers do not have the opportunity to hear them often (e.g. food, games); (b) the word group Pronouns in the Vocabulary section has been changed because the Slovenian instructions include gender variations and numerical categories that cannot be expressed for English; (c) the word group Quantifiers and identifiers in the Vocabulary section was also changed because in Slovenian there are no articles; these were replaced with identifiers; (d) because Slovenian has only one auxiliary verb 'to be', several modal words that have the function of auxiliary verbs in Slovenian were added to the word group Helping words and modal verbs in the Vocabulary section; (e) the Overgeneralization of Syntax Rules section was changed considerably. It contains thirty-nine pairs of words with correct or incorrect endings in noun declensions and verb conjugations. The errors given in this section are predictable developmental errors in Slovenian morphology. Parents mark 
whether their toddlers use the word with the correct or incorrect ending, or do not use either ending.

During the period in which the two inventories were adapted, the pilot version of the CDI: Words and Sentences, which included a vast majority of items included in the final version (with a few words changed in the Vocabulary section and changes made considering the titles of individual sections and the scoring in the Overgeneralization of Syntax Rules section), was used to examine the effect of gender and parental education on the communicative abilities of 953 toddlers aged from $\mathrm{I} ; 4$ to 2;6 (Marjanovič-Umek, Fekonja, Kranjc \& Bajc, 2008). The results showed significant differences in the scores of boys and girls in all of the inventory sections, but the effect of gender was small, while the parental education had a statistically significant positive effect on toddlers' scores in four of the seven sections (Vocabulary, How Often Toddlers Use Words, Mean Length of Utterance, and Complexity) included in the CDI: Words and Sentences.

The validity was estimated for CDI: Words and Sentences through the agreement of the parents' and teachers' estimations of toddlers' vocabulary and grammar on the sample of I40 Slovenian toddlers aged I;4 to $2 ; 6$, showing that, by controlling for the toddlers' age, the correlations between parents' and preschool teachers' assessments were positive and statistically significant in all the sections (Vocabulary: $r=0.54$; Past and Future Activities and Absent Things or Persons: $r=0.36$; Word Form and Meaning: $r=0.39$; Overgeneralization of Syntax Rules: $r=0.43$, Mean Length of Utterance: $r=0.55$; and Sentence Complexity: $r=0.43$ ) (Marjanovič-Umek, Fekonja-Peklaj, Podlesek \& Kranjc, 20 I I).

A questionnaire was added to the inventories, in which the parents enter information on potential illness or developmental delay in their infants or toddlers and their level of education.

\section{Procedure}

After collecting the parents' permission for their infants and toddlers to participate in the study, we gave the CDI: Words and Gestures and CDI: Words and Sentences to the mothers in three ways: the parents of infants and toddlers that were enrolled at preschool received the materials from their preschool teachers; parents that signed the permission form at the health clinic for preschool children received the materials from the paediatrician; and parents that signed the permission form using a parenting website received the materials electronically. Mothers filled in the forms at home and either returned them in a sealed envelope to their preschool teachers or mailed them to the researchers. Mothers that filled in the forms electronically sent them back electronically. 
RESULTS

Because of the small samples of infants and toddlers in separate age groups (by single months), they were grouped according to age into two-month intervals.

\section{Growth of vocabulary size in infants/toddlers aged $0 ; 8$ to $2 ; 6$}

Infants' and toddlers' understanding of words in the period between $0 ; 8$ and I ; 4 was assessed to be higher than their expressive vocabulary. The ratio of mean number of words understood and mean number of words spoken was $30 \cdot 6: 1 \cdot 9$ for infants aged $0 ; 8$ to $0 ; 9$, го7.8:14.4 for those aged o; Io to ०; I I, I 48.2: I $8 \cdot 9$ for those aged I ; O to I ; I, and 200.3:43. I for those aged $\mathrm{I} ; 2$ to $\mathrm{I} ; 3$.

The analysis of the growth of infants' and toddlers' expressive vocabulary in the period between aged $0 ; 8$ and $2 ; 6$ showed that the increase in expressive vocabulary follows an accelerated function (see Figure I). Different growth functions were compared. The $R^{2}$ for the linear function was $0.484(F(\mathrm{I}, 5 \mathrm{IO})=477.68, p<0.00 \mathrm{I})$. The $R^{2}$ for the quadratic function was $0.5 \mathrm{I} 8, R^{2}$ change $=0.035(F(\mathrm{I}, 509)=36.84, p<0.00 \mathrm{I})$, showing that the quadratic term statistically significantly improved the prediction of vocabulary. The $R^{2}$ for the cubic function was $0.520, R^{2}$ change $=0.00 \mathrm{I}$ $(F(\mathrm{I}, 508)=\mathrm{I} \cdot 5 \mathrm{I}, p=0.2 \mathrm{I} 9)$, which is why we chose the more parsimonious quadratic function to describe vocabulary growth. To reduce the multicollinearity of the linear and the quadratic term, age was grand mean centred before the regression coefficients were estimated. The final equation was: Vocabulary $=\mathbf{I} 26 \cdot 39-22 \cdot 84$ Age $+\mathrm{I} \cdot 035 \mathrm{Age}^{2}$. In this function, all the terms were significantly different from $\circ$ (for the linear term, $t=\mathbf{2} 3 \cdot \mathbf{2} 8$, $p<0.00 \mathrm{I}$; for the quadratic term, $t=6.07, p<0.00 \mathrm{I}$; for the constant, $t=\mathrm{I} 5 \cdot 47, p<0 \cdot 00 \mathrm{I})$.

To examine how infants' and toddlers' use of different word forms develops over time, we split toddlers into three age groups (taking into account considerable increases in the vocabulary size, we determined three age periods: 0 ; I I to I;2, I;7 to I; IO, and $2 ; 3$ to $2 ; 6$ ) and examined the percentage of different types of words used in each infant's or toddler's vocabulary. Average percentages across the infants and toddlers were then calculated for each word form. Relative comparisons of the average percentages in different age groups are shown in Figure 2. It is evident that in the youngest group (O; I I to I;2) the average infant or toddler only used interjections and nouns. In the middle group $(\mathrm{I} ; 7$ to I; IO), the relative percentage of these two word forms decreased as other forms of words emerged in the vocabulary: adjectives, verbs, adverbs, pronouns and particles. In the oldest group $(2 ; 3$ to $2 ; 6)$, all forms of words were present. With age, the relative percentage of 


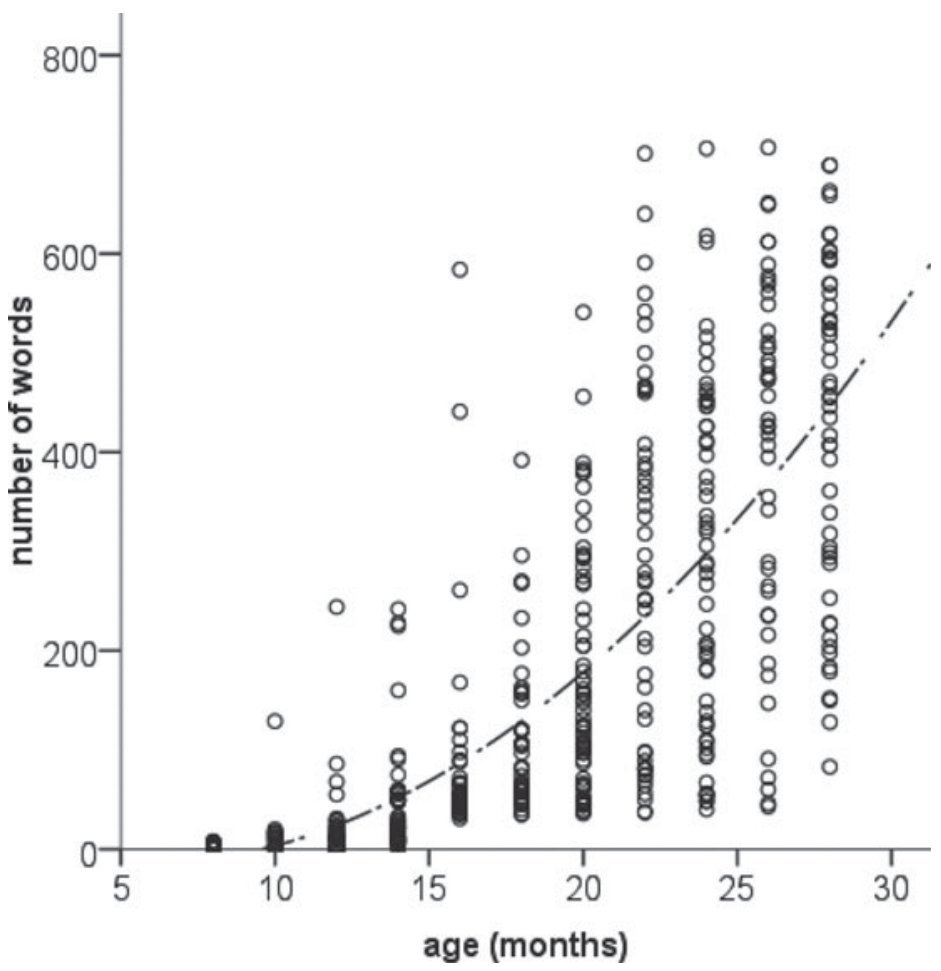

Fig. I. Growth of expressive vocabulary with age with the estimated quadratic function inserted.

interjections decreased notably and there was a large increase in toddlers' use of verbs.

In the next step we examined how the use of different word forms is related to the size of expressive vocabulary controlled for age. We first regressed vocabulary size on age using a quadratic curve estimation and calculated standardized residuals. Toddlers were then split into three groups: the low vocabulary group $(n=72)$ had standardized residuals lower than $-\mathrm{I}$, the medium vocabulary group $(n=359)$ had standardized residuals between $-\mathrm{I}$ and $+\mathrm{I}$, and the high competence group $(n=8 \mathrm{I})$ was composed of toddlers with standardized residuals greater than + I. Figure 3 shows the average percentages of different word forms in the three groups. With the increase in the size of expressive vocabulary in toddlers of the same age, the percentage of interjections and particles decreased, and the percentage of other word forms increased (most notably the share of verbs and adjectives). 


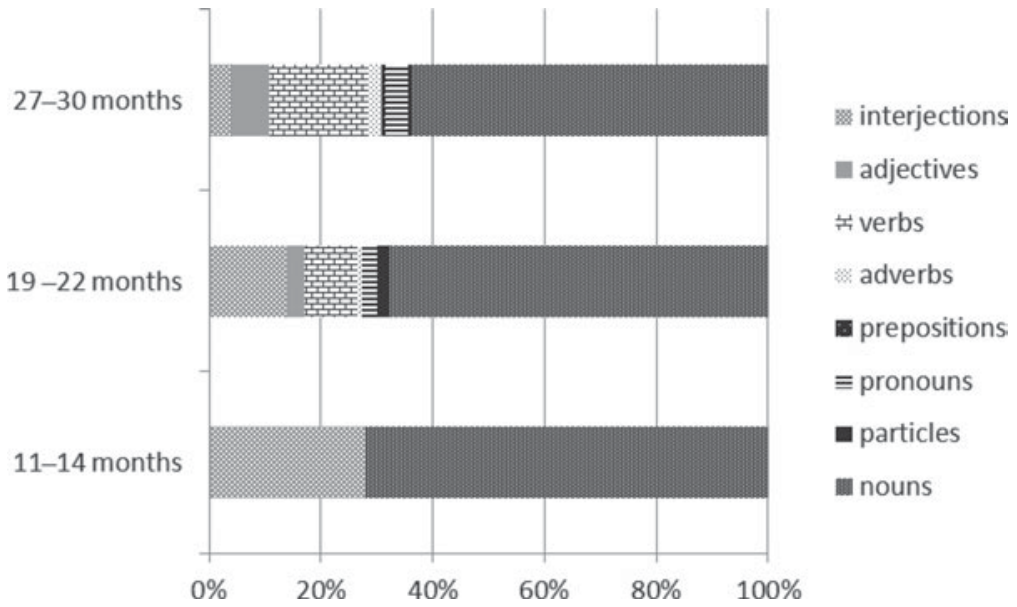

Fig. 2. The proportion of different word forms in the expressive vocabulary of infants or toddlers of different ages.

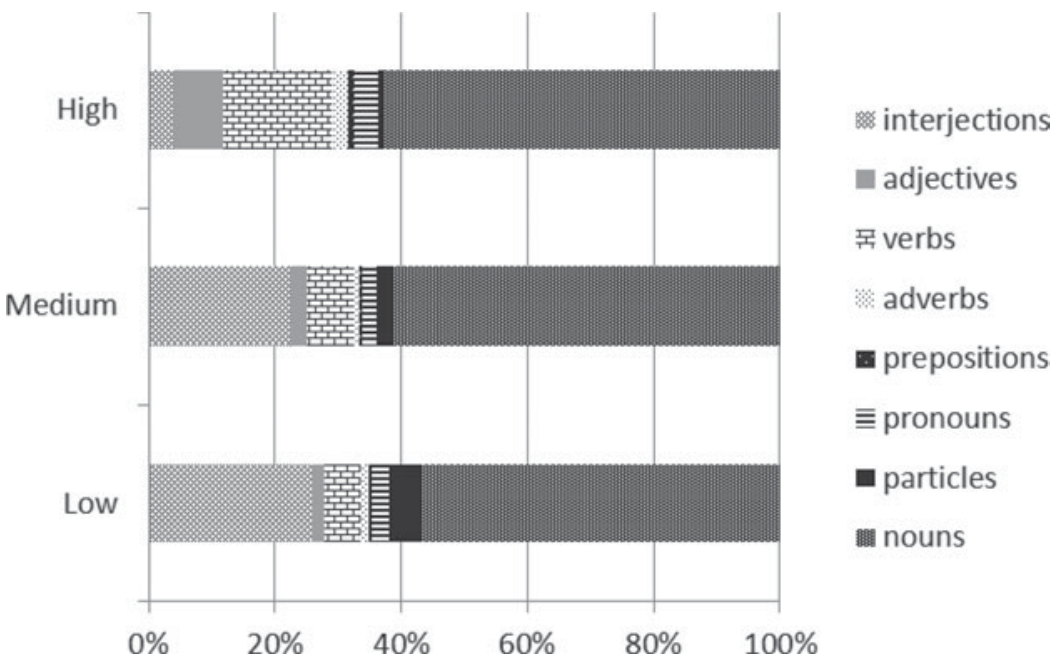

Fig. 3. Percentage of different word forms in three groups of toddlers with different size of expressive vocabulary controlled for age. The low group contains children whose vocabulary is more than I standard deviation below the mean vocabulary in children of the same age, and the high group contains children whose vocabulary is more than I standard deviation above the mean vocabulary in the comparative group. 
TABLE I. Correlations between infants' and toddlers' ages and various aspects of their communicative competence, and partial correlations between vocabulary and the use of gestures, controlling for the effect of age, in the group of infants/toddlers aged o; 8 to $\mathbf{1} ; 4$

\begin{tabular}{|c|c|c|c|}
\hline $\begin{array}{l}\text { Various aspects of communicative } \\
\text { competence measured with CDI : } \\
\text { Words and Gestures }\end{array}$ & $\begin{array}{l}\text { Infant/toddler age } \\
\quad(\text { zero-order } r)\end{array}$ & $\begin{array}{l}\text { Comprehensive } \\
\text { vocabulary } \\
(\text { partial } r)\end{array}$ & $\begin{array}{l}\text { Expressive } \\
\text { vocabulary } \\
\text { (partial } r \text { ) }\end{array}$ \\
\hline Phrases & $0.64 * * *$ & $0.56^{* * * *}$ & 0.14 \\
\hline Early-appearing gestures: Total score & $0.60 * * *$ & $0.50 * * *$ & $0.21 *$ \\
\hline First communicative gestures & $0.58 * * *$ & $0.42 * * *$ & O. I $8 *$ \\
\hline Games and routines & $0.50 * * *$ & $0.47^{* * * *}$ & $0 \cdot 20 *$ \\
\hline Actions with objects & $0.7 \mathrm{I} * * *$ & $0.47 * * * *$ & $0 \cdot 12$ \\
\hline Late-appearing gestures: Total score & $0.69 * * *$ & $0.53 * * *$ & $0 \cdot 19^{*}$ \\
\hline Pretending to be a parent & $0.45 * * *$ & $0.54^{* * * *}$ & $0.32 * * *$ \\
\hline Imitating adult actions & $0.65 * * *$ & $0.35 * * *$ & 0.08 \\
\hline
\end{tabular}

$* p<0.05 ; * * * p<0.001$.

Relations between infants' and toddlers' vocabulary and various aspects of their communicative competence

Next, we analyzed data within both groups of infants and toddlers: the younger ones $(0 ; 8$ to $\mathrm{I} ; 4)$ and the older ones $(\mathrm{I} ; 4$ to $2 ; 6)$ separately. In each age group, the increase in various aspects of communicative competence with age could be well approximated by a linear function. This is why we decided to simply use partial correlations to describe the relation between infants' and toddlers' vocabulary and various aspects of their communicative competence, controlling for the effect of age.

Table I shows the partial correlation coefficients between infants' and toddlers' vocabulary and other aspects of their communicative competence as measured with CDI: Words and Gestures and the zero-order correlation between infants' and toddlers' ages and understanding of phrases and the use of gestures. The zero-order correlation between an infant's or toddler's age and comprehensive vocabulary was $0.57(p<0.00 \mathrm{I})$, and between and infant's or toddler's age and expressive vocabulary it was $0.35(p<0.00 \mathrm{I})$. As expected, other aspects of their communicative competence were related to age as well. Over and above the correlation with age, infants' and toddlers' comprehensive vocabulary was positively related to their understanding of phrases as well as their use of early- and late-appearing gestures. According to Cohen (I992), these partial correlations were moderate to high. Partial correlations between the expressive vocabulary and other aspects of communicative competence were low.

In the group of toddlers aged I ; 4 to $2 ; 6$, vocabulary correlated positively with age $(r=0.62, p<0.00 \mathrm{I})$. Table 2 shows moderate to high zero-order correlations between other aspects of toddlers' communicative competence 
TABLE 2. Correlations between age and higher-level communicative competences, and partial correlations between vocabulary and these competences, controlling for the effect of age, in the group of toddlers aged I; 4 to 2;6

\begin{tabular}{lcc}
\hline $\begin{array}{l}\text { Various aspects of } \\
\text { communicative competence } \\
\text { measured with CDI }\end{array}$ & $\begin{array}{c}\text { Toddler age } \\
\text { Words and Sentences }\end{array}$ & $\begin{array}{c}\text { Vocabulary } \\
\text { (partial } r \text { ) }\end{array}$ \\
\hline $\begin{array}{l}\text { Past and future activities and } \\
\text { absent things or persons }\end{array}$ & $0.44^{* * * *}$ & $0.49^{* * * *}$ \\
$\begin{array}{l}\text { Word form and meaning } \\
\text { Mean length of utterance }\end{array}$ & $0.54^{* * * *}$ & $0.7 \mathrm{I}^{* * * *}$ \\
Sentence complexity & $0.58^{* * *}$ & $0.66^{* * * *}$ \\
$0.55^{* * *}$ & $0.69^{* * * *}$ \\
\hline
\end{tabular}

$* * * * 0.001$

measured with CDI: Words and Sentences and age. Moderate to high partial correlations between toddlers' vocabulary and the mean length of their utterances, the grammatical complexity of their sentences, and the use of word endings in their speech were found when controlling for the effect of age. Figures 4 and 5 show the relationship between the toddlers' Vocabulary scores and the Sentence complexity and MLU. It can be seen that the grammatical complexity and the length of toddlers' utterances increase as a function of their vocabulary size, with both measures of the grammatical completeness of toddlers' utterances increasing faster with greater vocabulary.

Finally, we used binary logistic regression to predict whether the toddler combines words into a sentence or not. A toddler's age and scores on three sections of the CDI: Words and Sentences (Vocabulary, Past and Future Activities and Absent Things or Persons, and Word Form and Meaning) were entered simultaneously into the model as predictors. Mean Length of Utterance and Sentence Complexity were not included as predictors because they are dependent on the toddler's use of multiword utterances. The model showed a proper fit (Hosmer-Lemeshow $\chi^{2}(8)=7 \cdot 43, p=0 \cdot 49 \mathrm{I}$, Nagelkerke $R^{2}=0.706$, and the overall percentage of correctly classified cases rose from $65 \cdot 6$ in the null model to $87 \cdot 2$ in the model with predictors). Factors that had a statistically significant role in predicting combining words into sentences were the size of a toddler's vocabulary and referring to past and future activities and absent things or persons (see Table 3). With every increase of one word in vocabulary, the probability that a toddler combines words into sentences increases by $\mathrm{I} \cdot 4 \%$. With a $\mathrm{I}$-point increase in the score on the Past and Future Activities and Absent Things or Persons section, this probability increases by $34 \cdot 1 \%$. 


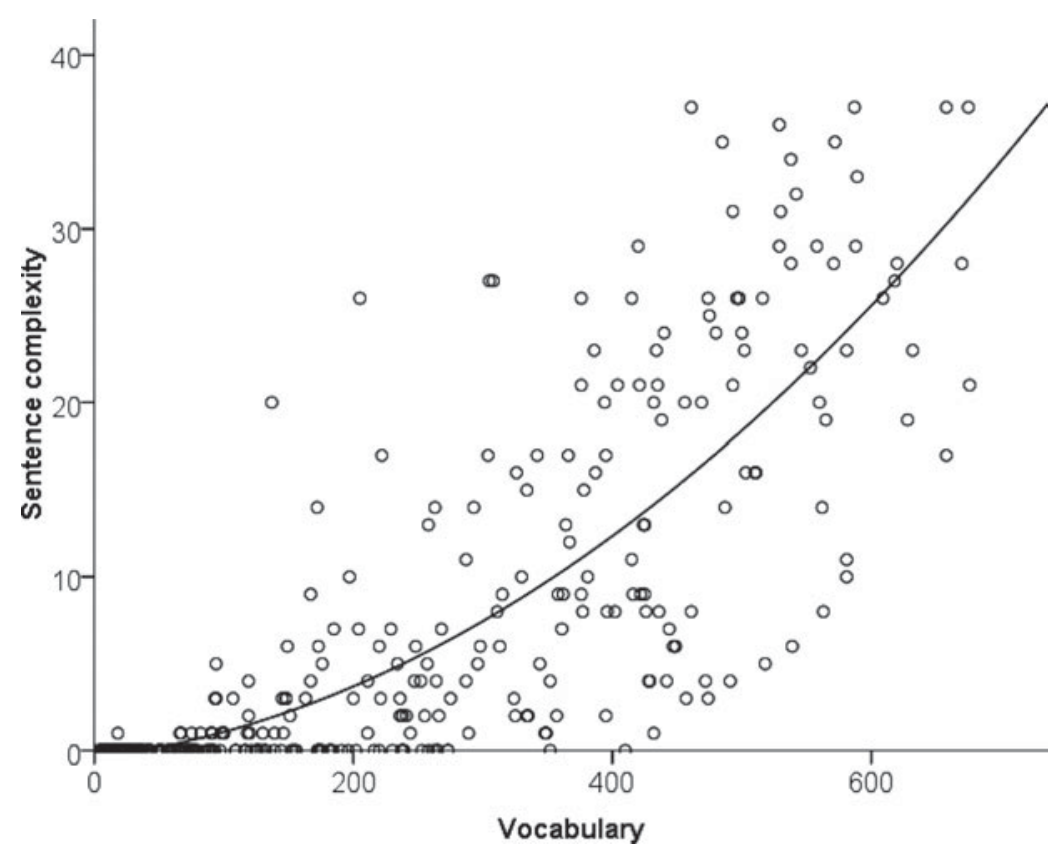

Fig. 4. The relation between sentence complexity and expressive vocabulary, assessed with CDI : Words and Sentences.

\section{DISCUSSION}

Our findings support the findings of several other authors (e.g. Bates \& Goodman, 200I; Fenson et al., I994), showing that infants and toddlers understand words before they use them. We established that there was a relatively large difference between the number of words infants and toddlers of a given age understand and those they speak; infants aged $0 ; 8$ and $0 ; 9$, who on average spoke $\mathrm{I} \cdot 9$ words, understood $30 \cdot 6$ words on average; and those aged I ; 2 and I ; 3 , who on average spoke $43 \cdot \mathrm{I}$ words, understood $200 \cdot 3$ words on average. Our findings have also indicated that the early vocabulary of Slovenian-speaking infants and toddlers increases with a quadratic function during the period from age $0 ; 8$ to $2 ; 6$, which means that the vocabulary growth accelerates over time; for example, the infants aged $0 ; 8$ or 0 ; 9 speak their first words; on average a one-year-old speaks i 8.9 words, a one-and-a-half-year-old 79 words, a two-year-old $256 \cdot 3$ words, and a two-and-a-half-year-old $393 \cdot 8$ words. However, substantial differences were detected in the expressive vocabulary of toddlers of the same age (see Figure I), which has also been established by other researchers (e.g. Bates, I999; Fernald et al., 200I). A comparison of vocabulary scores (word comprehension and use) between the Slovenian-speaking toddlers and the 


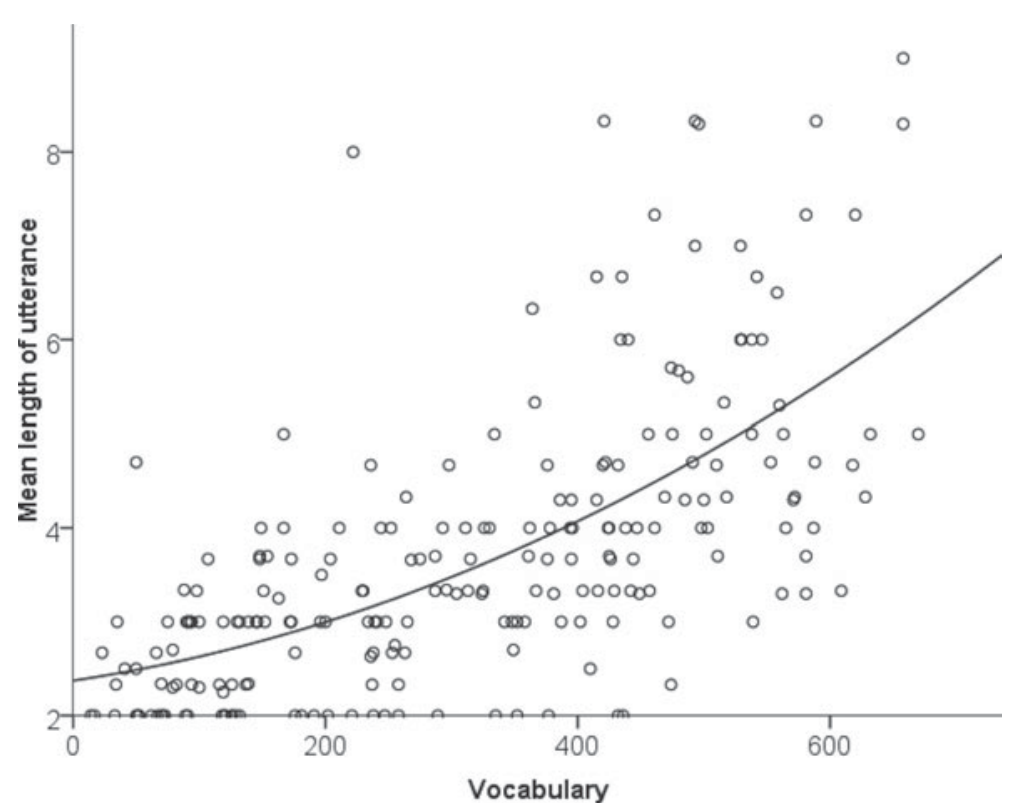

Fig. 5. The relation between mean length of utterance and expressive vocabulary, assessed with CDI : Words and Sentences.

English-speaking toddlers included in the standardization of the original CDI (Fenson et al., I994) shows that in general the vocabulary scores in individual age groups are similar. Greater differences between both samples of infants and toddlers aged $0 ; 8$ to $\mathrm{I} ; 4$ can be found with regard to the number of words they understand from the age of 0 ; I 0 to I; 3 . Slovenian infants and toddlers aged $\circ$; 10 to $\circ$; I I understand an average of 107 words, whereas the average vocabulary score of English-speaking toddlers (Fenson et al., I 994) show that they understand approximately 70 to 80 words at this age; Slovenian-speaking toddlers aged I; O to I; I understand an average of 148 words, and English-speaking toddlers of the same age understand approximately 80 to I 20 words; Slovenian-speaking toddlers aged I; 2 to I ; 3 understand an average of 200 words, whereas English-speaking toddlers understand approximately i 60 to 175 words at this age. A comparison of the expressive vocabulary between Slovenian- and English-speaking children aged $0 ; 8$ to $2 ; 6$ does not show that Slovenian-speaking toddlers speak more words; on the contrary: at the age of $\mathrm{I} ; 4$ to $2 ; 6$ they speak slightly fewer words than the English-speaking toddlers.

A greater difference in the number of spoken words, was recorded among different age groups of Slovenian-speaking toddlers aged $1 ; 6$ to $2 ; 0$ (the vocabulary scores of these age groups varied from 46 words at $\mathrm{i} ; 6$ to 238 
TABLE 3. Results of binary logistic regression for predicting combining words into sentences

\begin{tabular}{|c|c|c|c|c|c|c|c|}
\hline Predictor & $b$ & $S E_{\mathrm{b}}$ & Wald & $D f$ & $p$ & OR & $95 \% \mathrm{CI}$ for OR \\
\hline Constant & -5.568 & I.253 & I9.747 & I & $<0.001$ & 0.004 & \\
\hline Age & 0.076 & 0.056 & $\mathrm{I} \cdot 828$ & I & $0 \cdot 176$ & I.079 & $0 \cdot 966-I \cdot 205$ \\
\hline Vocabulary & 0.014 & 0.003 & $22 \cdot 289$ & I & $<0.001$ & I.014 & $i \cdot 008-1 \cdot 020$ \\
\hline $\begin{array}{l}\text { Past and future activities } \\
\text { and absent things } \\
\text { or persons }\end{array}$ & 0.677 & 0.182 & I 3.8 I 4 & I & $<0.001$ & I.969 & $\mathrm{I} \cdot 377-2 \cdot 8 \mathrm{I} 4$ \\
\hline Word form and meaning & 0.293 & 0.272 & $I \cdot 160$ & I & $0.28 \mathrm{I}$ & I.34I & $0.786-2 \cdot 287$ \\
\hline
\end{tabular}

NOTE: OR denotes odds ratio.

words at $2 ; 0$ ) and those aged $2 ; 0$ to $2 ; 6$ (the vocabulary scores of these age groups varied from 255 words at 2 ; 0 to 424 words at $2 ; 6$ ). These findings, although the study is not a longitudinal one, might indicate the occurrence of the two leaps in the development of vocabulary in this age period, thus matching the findings established by Bates and Goodman (200I), who reported that the first leap in the development of vocabulary of English-speaking toddlers occurs between ages I ; 4 and I ; 8, and the second between 2 ; 0 and $2 ; 6$. A more detailed analysis of the vocabulary in terms of different word forms used showed that the first vocabulary of infants and younger toddlers (aged o; I I to I ; 2), which included I I words on average, consisted of nouns and interjections; the vocabulary of toddlers in the second age group ( $1 ; 7$ to I; IO), which included 94 words on average, already consisted of more word forms (i.e. adjectives, verbs, adverbs, and pronouns), but the share of nouns and interjections decreased somewhat; the vocabulary of toddlers in the third age group $(2 ; 3$ to $2 ; 6)$, which consisted of 402 words, included all the word forms (i.e. interjections, nouns, verbs, adjectives, adverbs, pronouns, prepositions, and particles). Compared to other word forms, the share of nouns was the highest in the vocabulary of infants and toddlers in all three age groups. With age, the share of interjections decreased the most in the vocabulary of toddlers in all three age groups, whereas the share of verbs increased the most. Similarly, when we examined how the use of different word forms is related to the score of expressive vocabulary controlled for age, the results indicated that, with the increase in expressive vocabulary scores in toddlers of the same age, the percentage of interjections and particles, but not nouns, decreased. The major increase was observed in the percentage of verbs and adjectives. The overall percentage of open-class words (nouns, verbs and adjectives) was relatively high in the vocabulary of Slovenian-speaking toddlers in relation to closed-class words (such as prepositions, pronouns and adverbs). Whereas adjectives did not appear in the vocabulary of toddlers aged o; I I 
to $\mathrm{I} ; 2$, the percentage of adjectives was the third-largest word group (with the first being nouns and the second verbs) in the vocabulary of toddlers aged $2 ; 3$ to $2 ; 6$. The percentage of closed-class words increased with both toddlers' age and vocabulary scores. The results obtained match the findings of Conboy and Thal (2006), who established that toddlers tend to produce open-class or content words such as nouns, verbs and adjectives earlier than closed-class words such as prepositions, determiners and pronouns. The authors also report that at first the percentage of nouns increases and then starts decreasing with increasing vocabulary; however, the results of our study show that the percentage of nouns in the vocabulary slightly decreased with toddlers' age, but remained stable or slightly increased with the increasing vocabulary score. The results obtained only partly match those reported by Bornstein et al. (2004), who stated that in the vocabulary of infants aged $\mathrm{i} ; 8$ speaking various languages the share of nouns predominated over the shares of other word forms; however, in the vocabulary of toddlers that included fewer than 50 words the share of nouns was comparable to that of verbs. The findings of this study show that, in addition to nouns, the first vocabulary of Slovenian-speaking toddlers aged o; I I to I ; 2 also included interjections, but not verbs.

The significant positive correlations found between toddlers and infants' age and their achievements on various parts of CDI: Words and Gestures and CDI: Words and Sentences show that between ages $0 ; 8$ and 2;6 there are important age-related changes in the development of infants' and toddlers' development of communicative competence. Significant positive correlations between the infants' and toddlers' achievements on the Vocabulary section and their achievements on other sections of both lists indicate that vocabulary is an important predictor of the development of infants' and toddlers' communicative competence. Infants and toddlers aged $0 ; 8$ to I 4 whose mothers reported they understood and spoke more words than their peers understood a larger number of simple utterances used by an adult; for example, Are you hungry? or Don't do that. They also used more early- and late-appearing gestures; they more frequently used the first communicative gestures referring to giving, pointing and reaching, and conventional communicative gestures indicating the emergence of infants' or toddlers' intentional communication with others; they engaged in a larger number of games and participated in more routine activities with adults; they performed more actions with objects, which indicate their understanding of different objects and their common use; they also performed more symbolic actions related to pretending to be a parent, and more actions with which they imitated adult activity. The findings obtained match those established by other researchers, who report that the development of language during infancy and toddlerhood is closely connected with the development of the application of gestures and symbolic 
actions; they explain this correlation with the development of toddlers' symbolic representation ability (e.g. Brooks \& Meltzoff, 2008; Lewis, Boucher, Lupton \& Watson, 2000; Lyytinen, Poikkeus \& Laakso, I 997; McCune-Nicolich, I98I).

Similar to the findings of authors that used the CDI to study English-speaking (Bates, I999; Fenson et al., I 994), Italian-speaking (Caselli, Casadio \& Bates, I999; Devescovi et al., 2005), Spanish-speaking (Jackson-Maldonado, Thal, Marchman, Bates \& Gutiérrez-Clellen, 2000), Danish-speaking (Bleses et al., 2008), and Finnish-speaking (Stolt et al., 2009) toddlers' language, our findings show that toddlers' vocabulary scores are related to their acquisition of grammar. Our findings indicate that toddlers aged $\mathrm{I} ; 4$ to $2 ; 6$ with a more extensive vocabulary more often used words to refer to past or future events or absent objects and persons; in addition, they more often used various forms and meanings of words (i.e. various prefixes and suffixes to form plurals, possessive forms, and perfective and imperfective verbs, as well as the auxiliary verb 'to be' to create the past form). A more extensive vocabulary, which at the same time also included different word forms, enabled toddlers to form longer multiword and grammatically more complex utterances. The findings confirm that vocabulary development correlates significantly with the development of grammar, suggesting that the new types of words that toddlers use enable them to combine and form words into utterances in various ways (e.g. Bates and Goodman, I997; Devescovi et al., 2005; D’Odorico \& Carubbi, 2003; Tomasello \& Bates, 200r). The relationship between vocabulary scores and the Sentence Complexity and the MLU, shown in Figures 4 and Figure 5, shows that the grammatical complexity of toddlers' utterances increases as a function of their vocabulary scores; a similar finding has been established by Bates (I999). Initially, both measures of the grammatical completeness of toddlers' utterances increase slowly, but they increase faster with greater vocabulary. Similar to the findings of researchers that used samples of English- and Italian-speaking children (Caselli et al., I 999; Devescovi et al., 2005), our results also show a non-linear correlation between the MLU and Sentence Complexity on the one hand, and vocabulary score on the other.

Regression analysis further confirmed the predictive value of toddlers' vocabulary, but not their age, on their acquisition of grammar by showing that with each additional word in toddlers' vocabulary the probability of them forming utterances increased by $\mathrm{I} \cdot 4 \%$; in contrast, when toddlers are able to refer to past or future events and to absent things and objects, the probability of them forming utterances increased by $34 \%$. Several researchers (e.g. D’Odorico \& Carubbi, 2003; Marchman \& Bates, 1994) have determined that toddlers' ability to combine words into utterances is connected with the size of their vocabulary. However, our findings, 
obtained on the sample of Slovenian-speaking toddlers, suggest that toddlers' ability to refer to past or future events and absent objects and persons is more significant for their ability to form utterances than is their vocabulary score.

Based on the findings obtained, it can be concluded that, similar to toddlers acquiring other languages, the early vocabulary of Slovenian-speaking toddlers is a good predictor of the acquisition of grammar at ages I; 4 to $2 ; 6$. Furthermore, vocabulary score is also related to the development of infants' and toddlers' early communicative gestures in the period between ages $0 ; 8$ and $\mathrm{I} ; 4$. These findings indicate the importance of promoting early vocabulary development, which enables infants and toddlers to successfully communicate with others by forming longer and more grammatically complex utterances. On the other hand, one must also mention certain deficiencies of our study: the data on infants' and toddlers' communicative competence were collected using a cross-sectional approach, which does not make it possible to draw conclusions about the developmental changes in the communicative competence and any potential predictive value of infants' and toddlers' vocabulary for their later language development; in addition, the infant and toddler samples in certain age groups were relatively small, and the assessment of the vocabulary and other areas of communicative competence are based on the assessments of mothers that have proven to be valid in several other studies, but they can be influenced by specific factors such as education, language knowledge and knowledge of infants' and toddlers' language development (e.g. Dale, Bates, Reznick \& Morisset, I989; Fenson et al., I994; Marjanovič-Umek, Fekonja, Podlesek \& Kranjc, 20 I I; Tardif et al., I 999), which can reduce the ability to generalize the results obtained.

\section{REFERENCES}

Bates, E. ( I 999). Natura e cultura nel linguaggio. In R. Levi-Montalcini, D. Baltimore, R. Dulbecco \& F. Jacob (series eds) \& E. Bizzi, P. Calissano \& V. Volterra (vol. eds), Frontiere della biologia. Il cervello di Homo sapiens, 24I-65. Rome: Istituto della Enciclopedia Italiana fondata da Giovanni Trecanni S.p.A.

Bates, E., Dale, P. \& Thal, D. (1995). Individual differences and their implications for theories of language development. In P. Fletcher and B. MacWhinney (eds), Handbook of child language, 96-I 5 I. Oxford: Basil Blackwell.

Bates, E. \& Goodman, J. C. (I997). On the inseparability of grammar and the lexicon: Evidence from acquisition, aphasia and real-time processing. Language $\Xi^{\circ}$ Cognitive Processes 12(5/6), 507-586.

Bates, E. \& Goodman, J. C. (200I). On the inseparability of grammar and the lexicon: Evidence from acquisition. In M. Tomasello and E. Bates (eds), Language development: The essential readings, I34-62. Oxford: Blackwell.

Bates, E., Marchman, V., Thal, D., Fenson, L., Dale, P., Reznick, J. S., Reilly, J. \& Hartug, J. (I 994). Developmental and stylistic variation in the composition of early vocabulary. Fournal of Child Language 21, 85-124. 
Bleses, D., Vach, W., Slott, M., Wehberg, S., Thomsen, P., Madsen, T. O. \& Basbol, H. (2008). Early vocabulary development in Danish and other languages: A CDI-based comparison. Fournal of Child Language 35, 6 I 9-50.

Bornstein, M. H., Cote, L. R., Maital, S., Painter, K., Par, S.-Y., Pascual L., Pêcheux, M.-G., Ruel, J., Venuti, P. \& Vyt, A. (2004). Cross-linguistic analysis of vocabulary in young children: Spanish, Dutch, French, Hebrew, Italian, Korean, and American English. Child Development 75(4), i I I 5-39.

Brooks, R. \& Meltzoff, A. N. (2008). Infant gaze following and pointing predict accelerated vocabulary growth through two years of age: A longitudinal, growth curve modelling study. Fournal of Child Language 35, 207-220.

Caselli, M. C., Casadio, P. \& Bates, E. (r999). A comparison of the transition from first words to grammar in English and Italian. Fournal of Child Language 26, 69-I I I .

Caselli, M. C., Casadio, P. \& Bates, E. (200I). Lexical development in English and Italian. In M. Tomasello and E. Bates (eds), Language development: The essential readings, 76-I Io. Oxford: Blackwell.

Cohen, J. (I 992). A power primer. Psychological Bulletin II2, I 55-59.

Conboy, B. T. \& Thal, D. J. (2006). Ties between lexicon and grammar: Cross-sectional and longitudinal studies of bilingual toddlers. Child Development 77(3), 7 I 2-35.

Dale, P. S., Bates, E., Reznick, J. S. \& Morisset, C. (I989). The validity of a parent report instrument of child language at twenty months. Fournal of Child Language 16, 239-49.

Devescovi, A., Caselli, M. C., Marchione, D., Pasqualetti, P., Reilly, J. \& Bates, E. (2005). A crosslinguistic study of the relationship between grammar and lexical development. Fournal of Child Language 32, 759-86.

D’Odorico, L. \& Carubbi, S. (2003). Prosodic characteristics of early multi-word utterances in Italian children. First Language 23(I), 97-1 I6.

Fenson, L., Dale, P. S., Reznick, J. S., Thal, D., Bates, E., Hartung, J. P., Pethick, S. \& Reilly, J. S. (I994). MacArthur Communicative Development Inventories. User's guide and technical manual. Baltimore: Paul H. Brookes.

Fernald, A., Pinto, J. P., Swingley, D., Weinberg, A. \& McRoberts, G. W. (200ı). Rapid gains of verbal processing by infants in the 2 nd year. In M. Tomasello and E. Bates (eds), Language development: The essential readings, 49-56. Oxford: Blackwell.

Hoff, E. (200I). Components of word learning skill. Poster presented at the tenth European Conference on Developmental Psychology, Uppsala, Sweden.

Jackson-Maldonado, D., Thal, D., Marchman, V., Bates, E. \& Gutiérrez-Clellen, V. (2000). Early lexical development of Spanish-speaking infants and toddlers. Fournal of Child Language 20, 523-49.

Karmiloff, K. \& Karmiloff-Smith, A. (200I). Pathways to language. Cambridge, MA: Harvard University Press.

Lewis, V., Boucher, J., Lupton, L. \& Watson, S. (2000). Relationships between symbolic play, functional play, verbal and non-verbal ability in young children. International Fournal of Language and Communication Disorders 35(1), I I 7-27.

Lyytinen, P., Poikkeus, A.-M. \& Laakso, M.-L. (I997). Language and symbolic play in toddlers. International Fournal of Behavioral Development 21, 289-302.

Marchman, V. \& Bates, E. (r994). Continuity in lexical and morphological development: A test of the critical mass hypothesis. Fournal of Child Language 21(2), 339-66.

Marjanovič- Umek, L., Fekonja, U., Kranjc, S. \& Bajc, K. (2008). The effect of children's gender and parental education on toddler language development. European Early Childhood Education Research Fournal r6(3), 325-42.

Marjanovič- Umek, L., Fekonja, U., Podlesek, A. \& Kranjc, S. (20I I). Assessing toddler language competence: Agreement of parents' and preschool teachers' assessments. European Early Childhood Education Research fournal r9(I), 2 I-43.

Marjanovič-Umek, L., Fekonja- Peklaj, U., Sočan, G. \& Komidar, L. (20I I). Ocenjevanje sporazumevalnih zmožnosti dojenčkov in malčkov. Lista razvoja sporazumevalnih zmožnosti: Besede in geste in Lista razvoja sporazumevalnih zmožnosti: Besede in stavki. Priroc'nik [Assessing communicative abilities of infants and toddlers. Communicative Development 
Inventory: Words and Gestures. Communicative Development Inventory: Words and Sentences]. Ljubljana: Center for Psychology Diagnostic Resources.

McCune-Nicolich, L. (198I). Toward symbolic functioning: Structure of early pretend games and potential parallels with language. Child Development 52, 785-97.

Morgan, J. L., Shi, R. \& Allopena, P. (r996). Perceptual bases of rudimentary grammatical categories. In J. L. Morgan \& K. Demuth (eds), Signal to syntax, 263-86. Mahwah, NJ : Lawrence Erlbaum Associates.

Owens, R. E. (1996). Language development. Columbus, OH: Charles E. Merrill.

Reznick, J. S. \& Goldfield, B. A. (1994). Diary vs. representative checklist assessment of productive vocabulary. Fournal of Child Language 21, 465-72.

Siegler, R. S. (I 998). Children's thinking. Englewood Cliffs, NJ : Prentice Hall.

Stolt, S., Haataja, L., Lapinleimu, H. \& Lehtonen, L. (2009). Associations between lexicon and grammar at the end of the second year in Finnish children. Fournal of Child Language 36, 779-806.

Tardif, T., Gelman, S. A. \& Xu, F. (1999). Putting the 'noun bias' in context: A comparison of English and Mandarin. Child Development 7o(3), 620-35.

Thordardottir, E., Weismer, S. E. \& Evans, J. L. (2002). Continuity in lexical and morphological development in Icelandic and English-speaking 2-year-olds. First Language 22, 3-28.

Tomasello, M. \& Bates, E. (200I). General introduction. In M. Tomasello and E. Bates (eds), Language development: The essential readings, I-I I. Oxford: Blackwell. 